\title{
HUBUNGAN PERSONAL FACTORS DENGAN UNSAFE ACTIONS PADA PEKERJA PENGELASAN DI PT DOK DAN PERKAPALAN SURABAYA
}

\author{
Yusika Vienta Yudhawan*, Endang Dwiyanti* \\ Departemen Keselamatan dan Kesehatan Kerja \\ *Fakultas Kesehatan Masyarakat Universitas Airlangga \\ E-mail: yusikavienta@ymail.com
}

\begin{abstract}
ABSTRAK
Kecelakaan kerja merupakan kejadian yang tidak dikehendaki dan tidak diduga. Berdasarkan teori Loss Caution Model, penyebab langsung kecelakaan kerja yaitu unsafe actions dan unsafe conditions. Penyebab yang melatarbelakangi adanya unsafe actions yakni personal factors dan job factors. Penelitian yang dilakukan bertujuan untuk menganalisis adanya hubungan antara personal factors yang meliputi tingkat pengetahuan dan kelelahan dengan unsafe action yang dilakukan oleh pekerja pengelasan di PT Dok dan Perkapalan Surabaya. Penelitian ini bersifat observasional, dilakukan dalam satu waktu, dan merupakan penelitian analitik. Sampel diambil dari total populasi pekerja pengelasan sebanyak 22 responden. Variabel dalam penelitian ini adalah personal factors yang meliputi tingkat pengetahuan, kelelahan kerja, dan unsafe action. Pengumpulan data primer melalui kuisioner dan lembar observasi, sedangkan data sekunder diperoleh melalui data perusahaan yang terkait dengan penelitian yang dilakukan. Hasil penelitian menunjukkan bahwa tingkat pengetahuan pekerja pengelasan baik $(54,5 \%)$, pekerja pengelasan merasa kurang lelah $(50 \%)$ dan unsafe action yang dilakukan dalam kategori sedang $(68,2 \%)$. Berdasarkan uji statistik yang dilakukan diperoleh nilai signifikansi sebagai berikut: tingkat pengetahuan (sig 0,035$)$ dan kelelahan $(0,039)$. Hal tersebut menunjukkan bahwa terdapat hubungan antara personal factors yaitu tingkat pengetahuan dan kelelahan dengan unsafe action pada pekerja pengelasan di PT Dok da Perkapalan Surabaya. Disarankan perlu adanya safety talk untuk meningkatkan pemahaman dan kewaspadaan pekerja saat bekerja. Selain itu, perlu dilakukan pengaturan jam kerja untuk mengurangi kelelahan.
\end{abstract}

Kata Kunci : Unsafe Action, Pengetahuan, Kelelahan

\section{ABSTRACT}

Work accident is an occurrence that undesirable and unexpected. Based on Loss Causation Model's theory, the direct cause of workplace accidents is unsafe actions and unsafe conditions. The cause behind the unsafe actions is personal factors and job factors. This research aims to analyze the relationship between personal factors, which include knowledge and fatigue with unsafe action by welder in PT Dok and Perkapalan Surabaya. This research is observational research, cross sectional study, and an analytical study. Samples were taken of the total working population of welder as much as 22 respondents. The variables in this study are personal factors, which include knowledge, fatigue, and unsafe action. The collection of primary data through questionnaires and observation sheets, while secondary data obtained through the company's data related to the research conducted. The results showed that the level of knowledge of welding workers are good (54.5\%), welding workers feel less tired (50\%) and unsafe action undertaken in the medium 
category (68.2\%). Based on statistical tests performed significance value as follows: the level of knowledge (sig 0.035) and fatigue (0.039). It shows that there is a relationship between personal factors, which is the level of knowledge and fatigue with unsafe action on welding worker in PT Dok dan Perkapalan Surabaya. Suggested the need for safety talk to increase understanding and awareness of workers at work. In addition, necessary to regulate working hours to reduce fatigue.

Keywords : Unsafe Action, Knowledge, Fatigue

\section{PENDAHULUAN}

Kecelakaan merupakan kejadian yang tidak terduga karena tidak ada unsur kesengajaan maupun perencanaan dan tidak diharapkan. Kecelakaan akibat kerja adalah kecelakaan yang berhubungan dengan hubungan kerja pada perusahaan. Hubungan kerja yang dimaksud bahwa kecelakaan kerja terjadi dikarenakan oleh pekerjaan atau pada waktu melaksanakan pekerjaan (Suma'mur, 2014).

Menurut Frank Bird dalam Ramli (2010), kecelakaan kerja merupakan kejadian yang tidak diinginkan yang berdampak pada sesorang maupun kerusakan material, yang merupakan hasil dari adanya kontak dengan sumber energi kinetik, elektrik, kimia, panas, dan lain sebagainya. Dalam proses terjadinya kecelakaan terkait empat unsur produksi yaitu People, Equipment, Material, Environment yang saling berinteraksi dan bersama-sama menghasilkan suatu produk atau jasa

Berdasarkan data yang diperoleh dari International Labour Organization (ILO) pada tahun 2013, 1 pekerja di dunia meninggal setiap 15 detik karena kecelakaan kerja dan 160 pekerja mengalami sakit akibat kerja. pada tahun 2012, ILO mencatat angka kematian yang disebabkan kecelakaan dan penyakit akibat kerja (PAK) sebanyak 2 juta kasus setiap tahun (Departemen Kesehatan, 2014).

Menurut Frank E Bird dan George L Germain, terdapat tiga jenis tingkat kecelakaan berdasarkan efek yang ditimbulkan, yaitu incident, accident, dan nearmiss. Berdasarkan penelitian yang dilakukan oleh Birds, diketahui bahwa setiap satu kecelakaan berat disertai oeh 10 kejadian kecelakaan ringan, 30 kejadian kecelakaan yang menimbulkan kerusakan harta benda, dan 600 kejadian hampir celaka (Suardi, 2007).

Penyebab dari kecelakaan kerja dibagi menjadi dua golongan, yakni faktor mekanis dan lingkungan dan faktor manusia (Suma'mur, 2014). Faktor mekanis dan lingkungan adalah faktor yang meliputi segala sesuatu selain faktor manusia. Misalnya menghilangkan pengaman pada alat kerja yang dapat berpotensi menyebabkan kecelakaan kerja atau cedera. 
Golongan kedua yaitu faktor manusia sendiri. Misalnya kurang pengetahuan tentang cara mengoperasikan peralatan yang dapat mengakibatkan kesalahan dalam pengoperasiannya sehingga memicu terjadinya kecelakaan kerja.

Beberapa teori mengenai kecelakaan kerja telah dikembangkan, khususnya terkait dengan faktor yang menyebabkan timbulnya kecelakaan kerja. Pada tahun 1931, Heinrich mengemukaan sebuah teori yang menyebutkan bahwa setiap kecelakaan kerja disebabkan adanya lima faktor berurutan yang digambarkan seperti domino. Teori yang dikenal dengan Teori Domino tersebut menjelaskan bahwa kecelakaan kerja dapat terjadi karena adanya kebiasaan, kesalahan seseorang, perbuatan, dan kondisi yang tidak aman, sehingga dapat menyebabkan kecelakaan dan cidera.

Teori tersebut kemudian dikembangkan kembali oleh Bird dan Germain. Menurut Frank E. Bird dalam Suardi (2007), kecelakaan kerja disebabkan secara langsung oleh unsafe actions dan unsafe conditions. Berdasarkan hasil penelitian, penyebab kecelakaan kerja 85\% disebabkan oleh unsafe actions (Suma'mur, 2014).

Penelitian yang dilakukan DuPont, tercatat bahwa kecelakaan kerja yang disebabkan oleh unsafe actions sebesar $76 \%$, sebesar $22 \%$ kecelakaan kerja disebabkan oleh kombinasi unsafe actions dan unsafe conditions, dan 4\% kecelakaan kerja disebabkan oleh unsafe conditions (DuPont dalam Wicaksono, 2014). Berdasarkan data di atas, diketahui bahwa sebagian besar kecelakaan kerja disebabkan kerena unsafe actions.

Dalam teori yang dikemukaan oleh Frank E. Bird, terdapat penyebab dasar yang mengakibatkan terjadinya unsafe actions maupun unsafe conditions yaitu personal factors dan job factors (Suardi, 2007). Penelitian yang telah dilakukan oleh Permana (2015) mengenai hubungan personal factors dengan unsafe actions, ditemukan bahwa sebagian besar tenaga kerja melakukan tindakan tidak aman dengan persentase sebesar $88,9 \%$ dan terdapat hubungan antara personal factors dengan unsafe actions. Personal factors atau faktor perorangan merupakan faktor yang berasal dari manusia. Personal factors antara lain kurang pengetahuan, kurang keterampilan, motivasi kurang baik, masalah fisik, dan mental (Suardi, 2007).

Pengetahuan merupakan hasil penginderaan dan merupakan faktor penting dalam membentuk tindakan seseorang. Berdasarkan penelitian yang dilakukan oleh Septiana (2014) mengenai faktor yang mempengaruhi unsafe actions pada pekerja pengantongan urea, didapatkan bahwa terdapat hubungan yang signifikan antara pengetahuan dengan unsafe actions. 
Berdasarkan teori dan beberapa hasil penelitian, diketahui bahwa kecelakaan kerja banyak disebabkan karena unsafe actions dan oleh karena itu perlu diteliti mengenai penyebab terjadinya unsafe actions yang ditinjau dari personal factors yang meliputi tingkat pengetahuan dan kelelahan pada pekerja untuk mengetahui upaya pencegahan yang sesuai dan tepat sasaran sehingga dapat meminimalisir terjadinya unsafe action maupun kecelakaan kerja.

PT Dok dan Perkapalan merupakan perusahaan yang kegiatan utamanya adalah memproduksi dan juga memperbaiki berbagai jenis kapal. Bidang usaha yang dilakukan antara lain memperbaiki kapal di atas dok apung, perbaikan kapal di atas air, pembuatan kapal dengan cara merombak fungsi kapal, perbaikan kapal pada saat kapal berlayar atau kapal mengalami kerusakan di pelabuhan lain, pembuatan kapal baru, pembuatan anjungan, tempat peristirahatan atau rumah di tambang minyak lepas pantai, dan penyediaan tenaga pendesainan kapal.

Dalam proses produksi dan perbaikan kapal, terdapat proses pengelasan (welding). Terdapat tiga jenis proses pengelasan yang digunakan di bagian pembuatan kapal baru dan perbaikan kapal di PT Dok dan Perkapalan Surabaya. Pelaksanaan pekerjaan las tidak terlepas dari adanya sumber bahaya yang dapat menyebabkan kecelakaan maupun penyakit yang berhubungan dengan pengelasan. Bahaya yang dapat terjadi dalam proses pengelasan yaitu bahaya sinar, bahaya listrik, bahaya debu dan gas, bahaya percikan api dan terak las, dan bahaya lainnya seperti kebakaran, ledakan, dan terjatuh.

Sepanjang tahun 2012 hingga tahun 2015 terdapat beberapa tingkat kecelakaan kerja yang terjadi di PT Dok dan Perkapalan Surabaya. Tingkat kecelakaan yang terjadi yakni kecelakaan ringan, sedang, berat, hingga kecelakaan yang mengakibatkan meninggal dunia.

Tabel 1. Distribusi Kecelakaan Kerja Berdasarkan Tingkat Kecelakaan Kerja di PT Dok dan Perkapalan Tahun 2010-2015

\begin{tabular}{|l|c|c|c|c|c|}
\hline Tingkat & \multicolumn{5}{|c|}{ Tahun } \\
\cline { 2 - 6 } $\begin{array}{c}\text { Kecela- } \\
\text { kaan } \\
\text { Kerja }\end{array}$ & $\mathbf{2 0 1 1}$ & $\mathbf{2 0 1 2}$ & $\mathbf{2 0 1 3}$ & $\mathbf{2 0 1 4}$ & $\mathbf{2 0 1 5}$ \\
\hline Ringan & 4 & 2 & 1 & 1 & 1 \\
\hline Sedang & 6 & 1 & 1 & 1 & 3 \\
\hline Berat & 0 & 0 & 0 & 0 & 1 \\
\hline $\begin{array}{l}\text { Mening- } \\
\text { gal }\end{array}$ & 0 & 0 & 0 & 0 & 0 \\
\hline Jumlah & 10 & 3 & 2 & 2 & 5 \\
\hline
\end{tabular}

Sumber: PT Dok dan Perkapalan Surabaya Terdapat beberapa jenis kecelakaan kerja yang sering terjadi seperti kesetrum, terjepit, tergencet, terpeleset, terbakar, terjatuh, tertimpa, kebakaran, dan lain sebagainya. Jenis kecelakaan kerja yang sering terjadi yakni tertimpa dan terjatuh, hal tersebut disebabkan karena pekerja melakukan tindakan tidak aman (Maulana, 2011). Berdasarkan observasi awal yang 
dilakukan, masih banyak ditemui pekerja pengelasan yang melakukan unsafe action.

Berdasarkan teori Loss Causation Model dan beberapa hasil penelitian, diketahui bahwa kecelakaan kerja banyak disebabkan karena unsafe actions dan oleh karena itu perlu diteliti mengenai penyebab terjadinya unsafe actions yang ditinjau dari personal factors yang meliputi tingkat pengetahuan dan kelelahan pada pekerja pengelasan di PT Dok dan Perkapalan Surabaya.

Tujuan penelitian ini adalah untuk menganalisis hubungan antara personal factors dengan unsafe actions pada pekerja pengelasan di PT Dok dan Perkapalan Surabaya sehingga dapat diketahui upaya pencegahan yang sesuai dan tepat sasaran untuk meminimalisir terjadinya unsafe action maupun kecelakaan kerja.

\section{METODE}

Jenis penelitian yang dilakukan yaitu penelitian analitik karena menganalisis mengenai hubungan antara dua variabel yaitu variabel dependen dan independen. Penelitian ini termasuk penelitian observasional karena pengumpulan data penelitian dilakukan secara langsung tanpa memberikan perlakuan terhadap subjek yang diteliti. Berdasarkan waktu pengamatan, penelitian ini termasuk penelitian cross sectional karena dilakukan dalam satu waktu.
Penelitian dilakukan di PT Dok dan Perkapalan Surabaya. Waktu penelitian yaitu pada bulan Januari-Juni 2016. Populasi dalam penelitian ini adalah semua pekerja pengelasan di PT Dok dan Perkapalan Surabaya sejumlah 22 orang. Sampel merupakan bagian dari populasi dan mewakili populasi yang akan diteliti. Pada penelitian ini, sampel diambil dari total populasi pekerja pengelasan di PT Dok dan Perkapalan.

Variabel dalam penelitian ini terdiri dari variabel dependen dan independen. Variabel dependen yang diteliti yaitu mengenai unsafe actions. Variabel independen dalam penelitian ini yaitu personal factors yang meliputi tingkat pengetahuan dan kelelahan. Pengumpulan data primer diperoleh dari observasi dan kuesioner. Observasi dilakukan secara langsung terkait unsafe actions, sedangkan kuesioner diberikan kepada responden yang menjadi sampel dalam penelitian. Pengumpulan data sekunder diperoleh dari dokumen perusahaan mengenai profil perusahaan, data kepegawaian, data kecelakaan, dan dokumen terkait dengan unsafe actions di PT Dok dan Perkapalan Surabaya.

Data yang diperoleh dianalisis menggunakan analisis univariat dan bivariat. Analisis univariat digunakan untuk menyajikan data yang diperoleh dalam bentuk tabel. Analisis bivariat digunakan 
untuk melihat hubungan dengan menggunakan uji korelasi Spearman dengan $\alpha=0,05$.

\section{HASIL DAN PEMBAHASAN}

Pekerjaan Pengelasan di PT Dok dan Perkapalan

PT Dok dan Perkapalan merupakan yang dalam proses produksinya tidak lepas dari proses pengelasan (welding). Pengelasan yang dilakukan PT Dok dan Perkapalan Surabaya terdiri dari tiga jenis pengelasan, yaitu pengelasan manual (SMAW), pengelasan FCAW-MIG, dan pengelasan semi auto (SAW).

Pegelasan manual

(SMAW)

merupakan

pengelasan

dengan

menggunakan elektroda logam yang terbungkus oleh fluks, pengelasan ini biasanya disebut juga dengan las busur. Pengelasan FCAW-MIG merupakan pengelasan busur listrik dengan menggunakan kawat elektroda yang dilindungi gas. Gas yang digunakan oleh PT Dok dan Perkapalan Surabaya adalah gas $\mathrm{CO}_{2}$. Pengelasan semi auto (SAW) merupakan pengelasan yang menggunakan logam cair yang ditutupi fluks yang diatur melalui suatu penampang fluks dan logam pengisi yang berupa kawat pejal diumpan secara terus menerus.

Terdapat instruksi kerja pada masingmasing pekerjaan yang dilakukan di PT Dok dan Perkapalan Surabaya. Pada pekerjaan pengelasan terdapat tiga instruksi kerja yaitu instruksi kerja pengelasan manual (SMAW), pengelasan FCAW-MIG, dan pengelasan semi auto (SAW). Instruksi kerja tersebut telah disosialisasikan kepada seluruh pekerja, sehingga pekerja dapat mengetahui peralatan yang digunakan, material kerja, serta petunjuk untuk melakukan pekerjaan pengelasan.

Pekerjaan pengelasan dilakukan baik di bengkel maupun di dok apung sesuai dengan pekerjaan yang diberikan. Pekerja pengelasan di PT Dok dan Perkapalan Surabaya (Persero) telah memiliki sertifikasi pengelasan dengan berbagai tingkat seperti sertifikasi pengelasan $2 \mathrm{G}$, $4 \mathrm{G}$, dan $6 \mathrm{G}$.

\section{Identifikasi Personal Factors Pekerja Pengelasan}

Personal factors yang diteliti terkait dengan tingkat pengetahuan dan kelelahan pekerja pengelasan. Pengetahuan merupakan hasil dari tahu, dan terjadi setelah sesorang melakukan penginderaan terhadap obyek tertentu. Penginderaan terjadi melalui penginderaan manusia, yakni indera penglihatan, pendengaran, penciuman, rasa dan raba. Sebagian besar pengetahuan manusia diperoleh melalui mata dan telinga (Notoatmodjo, 2003).

Pengetahuan yang diteliti berkaitan dengan informasi yang diketahui oleh pekerja pengelasan mengenai keselamatan 
dan kesehatan kerja, kecelakaan kerja, bahaya yang dapat ditimbulkan dari pekerjaan pengelasan, penggunaan alat pelindung diri, dan standar operasional prosedur atau instruksi kerja yang diterapkan di tempat kerja.

Tabel 2. Distribusi Tingkat Pengetahuan Pekerja Pengelasan di PT Dok dan Perkapalan Surabaya

\begin{tabular}{c|l|c|c}
\hline No & \multicolumn{1}{|c|}{$\begin{array}{c}\text { Tingkat } \\
\text { Pengetahuan }\end{array}$} & $\mathrm{n}$ & $\mathbf{( \% )}$ \\
\hline 1 & Baik & 12 & 54,5 \\
2 & Sedang & 9 & 40,9 \\
3 & Buruk & 1 & 4,5 \\
\hline \multicolumn{2}{c|}{ Jumlah } & 22 & 100,0 \\
\multicolumn{2}{c}{ Berdasarkan hasil penelitian, }
\end{tabular}

diketahui bahwa sebagian besar pekerja pengelasan mengerti mengenai keselamatan dan kesehatan kerja di tempat kerja. Personal factors selanjutnya yakni kelelahan. Kelelahan menunjukkan kondisi yang berbeda-beda dari setiap individu, tetapi semuanya bermuara pada kehilangan efisiensi dan penurunan kapasitas kerja serta ketahanan tubuh (Tarwaka, 2004). Kelelahan yang diteliti merupakan tingkat kelelahan pekerja pengelasan terkait dengan perasaan dan keluhan kelelahan yang dirasakan

Tabel 3. Distribusi Kelelahan Pekerja Pengelasan di PT Dok dan Perkapalan Surabaya

\begin{tabular}{c|l|c|c}
\hline No & Kelelahan & N & $(\%)$ \\
\hline 1 & Kurang & 11 & 50,0 \\
& Lelah & & \\
2 & Lelah & 9 & 40,9 \\
3 & Sangat & 2 & 9,1 \\
& Lelah & & \\
\hline \multicolumn{2}{l}{ Jumlah } & 22 & 100,0 \\
\hline
\end{tabular}

Sebanyak 11 pekerja pengelasan kurang lelah dengan persentase sebesar $50,0 \%$. Sedangkan terdapat sebanyak 9 pekerja pengelasan yang merasa lelah dengan persentase sebesar 40,9\%. Sebanyak 2 pekerja pengelasan merasa sangat lelah dengan persentase sebesar 9,1\%. Berdasarkan tingkat kelelahan yang dirasakan oleh pekerja pengelasan, sebagian besar pekerja tidak merasa lelah saat bekerja.

Identifikasi Unsafe Action Pekerja

\section{Pengelasan}

Tindakan tidak aman merupakan penyebab langsung terjadinya kecelakaan kerja yang dapat menimbulkan kerugian bagi pekerja itu sendiri maupun perusahaan. Dalam penelitian ini unsafe action pekerja pengelasan yang diteliti terkait dengan pekerjaan yang tidak sesuai standar, mulai dari menyiapkan peralatan hingga selesai melakukan pekerjaan pengelasan yang tidak sesuai dengan standar dan dapat menyebabkan terjadinya kecelakaan kerja maupun penyakit akibat kerja. Berdasarkan hasil penelitian diketahui bahwa sebagian besar pekerja pengelasan melakukan unsafe action sedang dengan persentase sebesar $68,2 \%$.

Tabel 4. Distribusi Unsafe Action Pekerja Pengelasan di PT Dok dan Perkapalan Surabaya

\begin{tabular}{l|l|c|c}
\hline No & $\begin{array}{c}\text { Unsafe } \\
\text { actions }\end{array}$ & $\mathrm{n}$ & $\mathbf{( \% )}$ \\
\hline 1 & Rendah & 4 & 18,2 \\
\hline
\end{tabular}




\begin{tabular}{|c|c|c|c|}
\hline No & $\begin{array}{l}\text { Unsafe } \\
\text { actions }\end{array}$ & $\mathrm{n}$ & $(\%)$ \\
\hline 2 & Sedang & 15 & 68,2 \\
\hline 3 & Tinggi & 3 & 13,6 \\
\hline \multicolumn{2}{|c|}{ Jumlah } & 22 & 100,0 \\
\hline
\end{tabular}

melakukan unsafe actions rendah dengan persentase sebesar 18,2\%. Sebanyak 15 pekerja melakukan unsafe actions sedang dengan persentase sebesar $68,2 \%$. Pekerja dengan unsafe actions tinggi sebanyak 3 orang dengan persentase sebesar $13,6 \%$.

\section{Hubungan antara Pengetahuan dengan}

\section{Unsafe Action}

Berdasarkan hasil penelitian dapat diketahui bahwa pekerja pengelasan dengan tingkat pengetahuan buruk cenderung melakukan unsafe action yang tinggi dengan persentase sebesar 4,5\%. Pekerja pengelasan dengan tingkat pengetahuan sedang, cenderung melakukan unsafe action sedang dengan persentase sebesar $36,4 \%$. Pekerja dengan pengetahuan sedang juga melakukan unsafe action tinggi dengan persentase sebesar $4,5 \%$.

Pekerja pengelasan dengan tingkat pengetahuan baik cenderung melakukan unsafe action sedang dengan persentase sebesar 31,8\%. Selain itu, dapat diketahui pula bahwa pekerja pengelasan dengan tingkat pengetahuan yang baik juga melakukan unsafe action yang rendah dengan persentase sebesar $18,2 \%$ dan juga ada yang melakukan unsafe action tinggi dengan persentase sebesar $4,5 \%$.
Hasil uji statistik menunjukkan bahwa nilai signifikansi sebesar 0,035 yang berarti terdapat hubungan antara pengetahuan dengan unsafe action pekerja pengelasan. Nilai koefisien korelasi sebesar $-0,452$ menunjukkan bahwa kuat hubungan antara pengetahuan dengan unsafe action termasuk sedang. Hal ini juga menunjukkan semakin tinggi pengetahuan pekerja pengelasan, maka semakin rendah unsafe action yang dilakukan.

Berdasarkan hasil penelitian diketahui bahwa pekerja dengan tingkat pengetahuan yang buruk melakukan unsafe action tinggi. Hasil penelitian tersebut sesuai dengan teori dari Ramli (2010) yang mengatakan bahwa seseorang yang melakukan tindakan tidak aman dapat disebabkan karena seseorang tersebut tidak mengetahui tentang bahaya, peraturan atau cara kerja yang aman sehingga melakukan kesalahan dalam melakukan pekerjaan hingga berakhir dengan kecelakaan.

Berdasarkan hasil penelitian diketahui pula bahwa pekerja pengelasan dengan tingkat pengetahuan baik juga melakukan unsafe action dengan persentase sebesar 4,5\%. Hal tersebut juga mendukung teori yang dikemukakan oleh Ramli (2010) bahwa salah satu penyebab tindakan tidak aman yaitu pekerja tersebut tidak mau melakukan pekerjaan sesuai dengan prosedur sehingga terjadi kecelakaan walaupun pekerja tersebut telah mengetahui 
dan mampu untuk melakukan pekerjaan. Faktor tersebut berkaitan dengan perilaku dan kepedulian pekerja mengenai keselamatan dan kesehatan kerja.

Menurut Notoadmojo (2003), pengetahuan tercakup dalam 6 tingkatan domain kognitif yaitu tahu, memahami, aplikasi, analisis, sintesis dan evaluasi. Berdasarkan hasil penelitian diketahui bahwa pekerja pengelasan telah mengetahui mengenai keselamatan dan kesehatan kerja, namun pekerja pengelasan belum memahami secara tepat mengenai manfaat dari penerapan keselamatan dan kesehatan kerja. Maka dari itu untuk mengurangi unsafe action pada pekerja pengelasan tidak cukup dengan hanya mengetahui bahaya pekerjaan maupun prosedur yang dilakukan namun juga memahami pentingnya menerapkan keselamatan dan kesehatan kerja.

Upaya yang dilakukan oleh PT Dok dan Perkapalan untuk meningkatkan pengetahuan pekerja pengelasan yakni dengan mengadakan pelatihan dan sertifikasi kepada pekerja pengelasan. Pekerja pengelasan di PT Dok dan Perkapalan telah memiliki sertifikasi pengelasan, namun diperlukan adanya peningkatan pemahaman mengenai keselamatan dan kesehatan kerja yang menginformasikan mengenai identifikasi bahaya pekerjaan khususnya pengelasan, dampak jika melakukan unsafe action, manfaat penggunaan alat pelindung diri, serta manfaat melakukan pekerjaan dengan aman.

Hal tersebut dapat dilakukan dengan melakukan safety talk sebelum memulai pekerjaan. Melalui safety talk diharapkan pekerja dapat lebih waspada dengan keselamatan dan kesehatan pekerja pengelasan itu sendiri dan dapat meminimalisir adanya unsafe action.

\section{Hubungan antara Kelelahan dengan \\ Unsafe Action}

Berdasarkan hasil penelitian dapat diketahui bahwa pekerja pengelasan dengan tingkat kelelahan ringan atau kurang lelah cenderung melakukan unsafe action sedang dengan persentase sebesar 27,3\%. Pekerja pengelasan yang merasa lelah melakukan unsafe action kategori sedang dengan persentase sebesar $36,4 \%$. Pekerja dengan tingkat kelelahan sangat lelah melakukan unsafe action sedang bahkan tinggi dengan persentase sebesar $4,5 \%$.

Hasil uji statistik menunjukkan nilai signifikansi sebesar $0,039 \quad$ yang menunjukkan bahwa terdapat hubungan antara kelelahan dengan unsafe action. Nilai koefisien korelasi sebesar 0,443 menunjukkan bahwa kuat hubungan antara kelelahan dengan unsafe action termasuk sedang. Berdasarkan uji statistik, diketahui bahwa semakin lelah pekerja pengelasan, maka tingkat unsafe action juga semakin tinggi. 
Hal ini sesuai dengan teori dari Suma'mur (2014) bahwa perasaan lelah yang tinggi dapat menyebabkan seseorang tidak mampu bekerja sehingga berhenti bekerja sebagaimana halnya kelelahan fisiologis yang mengakibatkan tenaga kerja menghentikan kegiatannya karena kelelahan.

Kelelahan mudah dicegah atau ditiadakan dengan berhenti bekerja atau beristirahat. Jika tenaga kerja mulai merasa lelah dan tetap harus bekerja, maka kelelahan akan semakin bertambah dan dapat mengganggu kelancaran pekerjaan serta berakibat buruk bagi tenaga kerja yang bersangkutan.

Hasil penelitian menunjukkan bahwa pekerja pengelasan yang kurang lelah dan pekerja yang merasa lelah cenderung melakukan unsafe action sedang. Hal tersebut sesuai dengan teori Loss Causation Model yang menyatakan bahwa unsafe action disebabkan stres fisik/fisiologis yang mencakup sakit, kelelahan karena beban atau durasi kerja yang terlalu berat, kelelahan karena kurang istirahat dan lain sebagainya.

Kelelahan juga dipengaruhi oleh kondisi lingkungan pekerjaan pengelasan seperti lingkungan kerja yang panas, kebisingan, suhu, dan lain sebagainya. Rasa lelah yang dialami pekerja bukan hanya saat melakukan pekerjaan, bahkan sebelum pekerja melakukan pekerjaan. Kelelahan dalam jangka waktu yang panjang dapat menjadi salah satu faktor yang mengakibatkan terjadinya unsafe action.

Hasil penelitian juga sesuai dengan teori dari Cameron dalam Setyawati (2010) bahwa kelelahan kerja merupakan respon individu terhadap stres psikososial yang dialami pekerja dalam periode waktu tertentu, kelelahan kerja menurunkan prestasi maupun motivasi serta berkaitan dengan adanya penurunan kinerja fisik dan produktivitas kerja.

Kelelahan dapat dikurangi dengan mengelola kondisi pekerjaan dan lingkungan kerja di tempat kerja. Pengaturan jam kerja dapat dilakukan untuk meminimalisir terjadinya kelelahan. Selain itu juga dapat memanfaatkan waktu istirahat untuk latihan fisik maupun peregangan sehingga dapat mengurangi kelelahan.

\section{SIMPULAN DAN SARAN}

Personal factors pekerja pengelasan yang diteliti meliputi pengetahuan dan kelelahan. Mayoritas pekerja pengelasan memiliki pengetahuan yang baik dan merasa kurang lelah.

Unsafe action yang dilakukan pekerja pengelasan antara lain tidak menggunakan alat pelindung diri dan alat pelindung diri tidak digunakan sesuai dengan standar. 
Unsafe action yang dilakukan termasuk dalam kategori sedang.

Terdapat hubungan antara personal factors (pengetahuan, kelelahan) dengan unsafe action dan kuat hubungan sedang.

Disarankan untuk melakukan safety talk saat apel pagi secara berkala untuk meningkatkan kewaspadaan pekerja saat akan melakukan pekerjaan. Mengatur jam kerja dan memanfaatkan waktu istirahat untuk melakukan peregangan untuk mengurangi dan mencegah kelelahan.

\section{DAFTAR PUSTAKA}

Adelina. 2015. Hubungan Antara Predisposing Factors, Enabling Factors Dan Reinforcing factors Dengan Perilaku Penggunaan APD di Bagian Pengelasan Divisi Kapal Perang PT. PAL Indonesia (Persero). Skripsi. Surabaya, Universitas Airlangga: 34.

Departemen Kesehatan. 2014. 1 Orang Pekerja di Dunia Meninggal Setiap 15 Detik Karena Kecelakaan Kerja. Berita dan Informasi Kecelakaan Kerja

(http://www.depkes.go.id/folder/view/ 01/structure-web-content-rilis-beritadan-informasi.html). Diakses 1 November 2015.

Harrianto, R. 2010. Buku Ajar Kesehatan Kerja. Jakarta: Penerbit Buku Kedokteran EGC.

Maulana, D. 2011. Evaluasi dan Perbaikan Sistem Manajemen Keselamatan dan Kesehatan Kerja (SMK3) untuk Menekan Unsafe Behavior Pekerja (Studi Kasus PT.DPS). Jurnal ITS
Notoatmodjo, S. 2003. Pendidikan dan Perilaku Kesehatan. Jakarta: Rineka Cipta

Oktavianti. 2014. Hubungan Faktor Internal dengan Unsafe Actions pada Pekerja Konstrusi Proyek Jalan Tol SurabayaMojokerto Seksi IV PT. Wijaya Karya (Persero). Skripsi. Surabaya, Universitas Airlangga: 22.

Permana, AD. 2015. Hubungan Personal Factors dengan Unsafe Action Proses Pemasangan Pipa Baja oleh PT Putra Negara Surabaya. Skripsi. Surabaya: Universitas Airlangga.

Ramli, S. 2010. Sistem Manajemen Keselamatan dan Kesehatan Kerja. Jakarta: Dian Rakyat.

Ramli, S. 2010. Manajemen Risiko dalam Perspektif K3 OHS Risk Management. Jakarta: Dian Rakyat.

Septiana, D. 2014. Faktor yang Mempengaruhi Unsafe Action pada Pekerja di Bagian Pengantongan Urea. Jurnal Vol 3, No.1 : 25-34.

Setyawati, L. 2010. Selintas tentang Kelelahan Kerja. Yogyakarta: Amara Books.

Suardi, R. 2007. Sistem Manajemen Keselamatan dan Kesehatan Kerja. Jakarta: Penerbit PPM.

Suma'mur. 2014. Higiene Perusahaan dan Kesehatan Kerja (Hiperkes). Jakarta: Sagung Seto.

Tarwaka H.A, Solicul, Sudiajeng, Lilik. 2004. Ergonomi untuk Kesehatan, Keselamatan Kerja dan Produktivitas. Surakarta: Uniba Press.

Tarwaka. 2014. Keselamatan dan Kesehatan Kerja (K3): Manajemen dan Implementasi K3 di Tempat kerja. Surakarta: Harapan Press.

Undang-Undang Republik Indonesia Nomor 1 Tahun 1970 Tentang Keselamatan Kerja.

Wicaksono, D. 2014. Penyebab Terjadinya Substandard Practice Berdasarkan Loss Causation Model Pada Pengelas di PT Bangun Sarana Baja. Jurnal Vol 1, No.1 : 2 . 